\title{
VALORAÇÃO ECONÔMICA DOS SERVIÇOS ECOSSISTÊMICOS DA ZONA COSTEIRA - O CASO DO PNMLJ PELO MÉTODO DO CUSTO DE VIAGEM
}

Otelino Nunes da Silva ${ }^{1}$ Marinez E. G. Scherer ${ }^{2}$

Resumo: Classificar e estimar o valor econômico dos serviços ecossistêmicos (SEs) da Zona Costeira poderá chamar a atenção da sociedade para a importância dos benefícios gerados pelos seus ecossistemas. Os SEs são aqueles prestados pelos ecossistemas aos seres humanos. Podem ser as qualidades ecológicas que tornam atraente as atividades recreativas, esportivas e a inspiração artística; como também, a água armazenada em aquíferos; o excedente populacional de peixes para alimentação humana; entre outros. Como estudo de caso utilizou-se a Unidade de Conservação Parque Natural Municipal Lagoa do Jacaré das Dunas do Santinho (PNMLJ), localizado na Praia do Santinho, no extremo nordeste da llha de Santa Catarina (ISC). Além da importância do PNMLJ pela diversidade dos seus ecossistemas naturais e dos seus SEs para o bem-estar da população, o local está situado entre importantes balneários que fomentam a economia do turismo de Florianópolis. A partir de um Sistema de Informações Geográficas (SIG) foram mapeados 6 ecossistemas naturais do PNMLJ (Mata Atlântica, Restinga, Duna, Costão rochoso, Banhado e Praial). A identificação, classificação e análise dos SEs do PNMLJ foram efetuadas com base em Costanza et al. (1997), MEA (2005), Maynard et al. (2010) e a Classificação Internacional de Serviços Ecossistêmico (CICES). Ao todo foram identificados 20 serviços ecossistêmicos, sendo: 4 de Provisão; 5 de Regulação e Manutenção; e, 11 Culturais. Desses últimos, 6 foram escolhidos para valorar economicamente o uso dos SEs Culturais relacionadas ao lazer e a recreação do PNMLJ pelo Método do Custo de Viagem (MCV). O MCV atribui o valor gasto por turistas para se deslocarem a um lugar, para recreação, como uma aproximação dos benefícios, ou do valor de uso, desse serviço de recreação. Os dados foram obtidos por meio de questionários aplicados a 33 turistas que visitaram o PNMLJ no período de janeiro a fevereiro de 2019. As variáveis utilizadas, extraídas dos dados da caracterização socioeconômica das entrevistas, foram o custo do tempo de viagem, o custo do transporte e o custo diário com deslocamentos, alimentação e hospedagem. O valor resultante do Uso do PNMLJ foi estimado em $\mathrm{R} \$ 25.897 .102,17$ por ano. Aos tomadores de decisão e gestores de áreas naturais remanescentes na Zona Costeira, cabe utilizar desses conhecimentos para acelerar os processos efetivos de preservação dessas áreas, seja por meio da elaboração e efetivação de planos de manejo; criação de novas Unidades de Conservação; entre outros. Além disso, o uso desses serviços pode ser taxado para a manutenção e conservação dos SEs, garantindo a qualidade de vida da sociedade humana e a renda proveniente do mercado turístico.

Palavras-chave: Zona costeira. Unidade de Conservação. Serviços ecossistêmicos. Valoração econômica ecossistêmica. Método do Custo de Viagem.

\footnotetext{
1 Universidade Federal de Santa Catarina, Programa de Pós-Graduação em Geografia da Universidade Federal de Santa Catarina (UFSC), Florianópolis, Brasil, otelino@gmail.com, https://orcid.org/0000-0002-1773-5885.

${ }^{2}$ Universidade Federal de Santa Catarina, Coordenadoria Especial de Oceanografia, Florianópolis, Brasil, marinez.scherer@gmail.com, https://orcid.org/0000-0002-3059-0019.
} 
ECONOMIC EVALUATION OF ECOSYSTEM SERVICES IN THE COASTAL ZONE - THE CASE OF THE MNPJL BY THE OF TRAVEL COSTS METHOD

\begin{abstract}
Classifying and estimating the economic value of ecosystem services (ES) in the Coastal Zone could draw attention of society to the importance of the benefits generated by its ecosystems. ES are those provided by ecosystems to human beings. It can be the ecological qualities that make it attractive as recreational, sporting and artistic inspiration, as well as water stored in aquifers, the population surplus of fish for human consumption; among others. As a case study we used the Conservation Unit of the Municipal Natural Park of the Jacaré Lagoon of the Dunes of Santinho (MNPJL), located in Santinho Beach, in the extreme northeast of Santa Catarina Island (SCI). In addition to the importance of the MNPJL due to the diversity of its natural ecosystems and its ES for the well-being of the population, the place is located among important beaches that foster the economy of Florianopolis tourism. Using a Geographic Information System (GIS), 6 natural ecosystems of the MNPJL were mapped (Atlantic Forest, Restinga, Dune, Rocky Coast, Bathed and Beach). The identification, classification and analysis of the MNPJL ES was carried out based on Costanza et al. (1997), MEA (2005), Maynard et al. (2010) and the Common International Classification of Ecosystem Services (CICES). In all, 20 ecosystem services were identified, of which: 4 for Provision; 5 Regulation and Maintenance; and, 11 Cultural. Of the latter, six cultural ES of recreation and leisure were chosen for economic valuation by the Travel Costs Method (TCM). The TCM attributes the amount spent by tourists to travel to a place, for recreation, as an approximation of the benefits, or the use value, of this recreation service. The data were obtained through questionnaires applied to 33 tourists who visited the MNPJL from January to February 2019. The variables used, extracted from the data of the socioeconomic characterization of the interviews, were the cost of travel time, the cost of transportation and the daily cost of travel, food and accommodation. The amount resulting from the Use of the MNPJL was estimated at $R \$ 25,897,281.78$ per year. Decision makers and managers of natural areas remaining in the Coastal Zone should use the knowledge presented here to accelerate the effective processes of preservation of these areas, either through the elaboration and implementation of management plans; creation of new Conservation Units; among others. In addition, the use of these services can be taxed for the maintenance and conservation of ES, guaranteeing the quality of life of human society and the income from the tourist market.
\end{abstract}

Keywords: Coastal Zone. Conservation Unit. Ecosystem services. Ecosystem economic valuation. Travel Cost Method (TCM).

\title{
VALORACIÓN ECONOMICA DE LOS SERVICIOS ECOSISTÉMICOS DE LA ZONA COSTERA - EL CASO DEL PNMLJ POR EL MÉTODO DE LOS COSTES DE VIAJE
}

Resumen: Clasificar y estimar el valor económico de los servicios ecosistémicos (SE) en la Zona Costera podrá llamar la atención de la sociedad sobre la importancia de los beneficios generados por sus ecosistemas. Los SE son los servicios que los ecosistemas ofrecen a los seres humanos. Pueden ser las cualidades ecológicas las que hacen atractivas las actividades recreativas, deportivas y la inspiración artística, así como el agua almacenada en los acuíferos, el excedente poblacional de peces para consumo humano; entre otros. Como estudio de caso, se utilizó el Parque 
Natural Municipal de la Lagoa del Jacaré de las Dunas del Santinho (PNMLJ), ubicado en Playa del Santinho, en el extremo noreste de la Isla de Santa Catarina (ISC). Además de la importancia del PNMLJ debido a la diversidad de sus ecosistemas naturales y sus SE para el bienestar de la población, el lugar se encuentra entre importantes centros turísticos que fomentan la economía turística de Florianópolis. A partir de un Sistema de Información Geográfica (SIG), se mapearon 6 ecosistemas naturales del PNMLJ (Mata Atlántica, Restinga, Duna, Costão Rocoso, Bañado y Playa). La identificación, clasificación y análisis de los SE del PNMLJ se realizó con base en Costanza et al. (1997), MEA (2005), Maynard et al. (2010) y la Clasificación Internacional de Servicios Ecosistémicos (CICES). En total fueron identificados 20 servicios ecosistémicos, siendo: 4 de Provisión, seguidos por 5 de Regulación y Mantenimiento; y, 11 Culturales. De estos últimos, 6 SEs culturales de recreación y ocio fueron elegidos para la valoración económica por el Método de los Costos de Viaje (MCV). EI MCV atribuye la cantidad gastada por los turistas para viajar a un lugar, para recreación, como una aproximación de los beneficios, o el valor de uso, de ese servicio de recreación. Los datos se obtuvieron mediante cuestionarios aplicados a 33 turistas que visitaron el PNMLJ de enero a febrero de 2019. Las variables utilizadas, extraídas de la caracterización socioeconómica de las entrevistas, fueron el costo del tiempo de viaje, el costo del transporte y el costo diario de viaje, comida y alojamiento. El valor resultante del Uso del PNMLJ fue estimado en R \$25.897.102,17 por año. A los tomadores de decisión y gestores de áreas naturales remanentes en la Zona Costera, cabe utilizar los conocimientos aquí expuestos para acelerar los procesos efectivos de preservación de esas áreas, sea por medio de la elaboración y puesta en marcha de planes de manejo; creación de nuevas unidades de conservación; entre otros. Además, el uso de estos servicios puede someterse a imposición para el mantenimiento y la conservación del SE, garantizando la calidad de vida de la sociedad humana y las recetas financieras del mercado turístico.

Palabras clave: Zona costera. Unidad de Conservación. Servicios ecosistémicos. Valoración económica ecosistémica. Método de Costes de Viaje.

\section{Introdução}

A Zona Costeira tem sido uma das áreas de maior concentração populacional (aproximadamente um quarto da população brasileira) incidindo um alto nível de pressão antrópica sobre os seus recursos naturais (MMA, 2010). Essa ocupação da linha de costa, por vezes desordenada, ocasiona a poluição e a supressão de seus ecossistemas (BARRAGÁN, 2016), impactado os ecossistemas costeiros (supressão de vegetação, descarte de lixo e esgoto, erosão praial) e consequentemente a qualidade de vida de seus habitantes (SILVA, 2010). Classificar e estimar o valor econômico dos serviços ecossistêmicos da Zona Costeira poderá chamar a atenção da sociedade para a importância dos benefícios gerados pelos seus ecossistemas.

É importante ressaltar que é nos ecossistemas que ocorrem os processos e componentes biológicos, geoquímicos e físicos (e.g.: regulação climática, regulação 
da água, regulação de nutrientes, retenção do solo, etc.) denominados de funções ecossistêmicas. São essas funções, por meio da interação de processos, que produzem bens e serviços que de forma direta ou indireta beneficiam a vida em todo o planeta (GROOT et al., 2002). Esses serviços, quando beneficiam os seres humanos são, então, de acordo com a Avaliação dos Ecossistemas do Milênio (MEA, 2005 p. 53 - da sigla em inglês Millennium Ecosystem Assessment) denominados de serviços ecossistêmicos (SEs).

Os SEs são, portanto, os fluxos ou saídas desses processos que são valorizados pelo seu benefício direto para os seres humanos (MAYNARD et al., 2010). Podem ser exemplificados como: o armazenamento da água pluvial na forma de um aquífero por um ecossistema de dunas; os peixes, crustáceos e moluscos para alimentação humana de um ecossistema praial; as qualidades ecológicas que tornam atraente as atividades recreativas e esportivas; e a inspiração artística por meio da paisagem fornecida por vários ecossistemas, etc.

Devido a essa importância dos ecossistemas naturais para o bem-estar humano, em especial os localizados na Zona Costeira (manguezais, praias, dunas, banhados, Mata Atlântica), pressionados pela intervenção antrópica, torna-se fundamental, para o ordenamento e gestão dos usos e atividades humanas nessas áreas, classificar e valorar os serviços ecossistêmicos ali existentes.

A classificação dos SEs tem sido discutida e estruturada por diversos autores, entre eles podemos citar: Costanza et al. (1997), MEA (2005), Maynard et al. (2010), Scherer \& Asmus (2016) e a Classificação Internacional Comum de Serviços Ecossistêmicos (CICES, da sigla em inglês Common International Classification of Ecosystem Services - versão $5.1,2018)$. Somado a isso, a quantificação dos serviços ecossistêmicos tem sido pontuada ${ }^{3}$ ou valorada economicamente ${ }^{4}$, pela comunidade científica em diversas regiões de estudo.

É fato que quando um bem ou um benefício não é trocado ou comercializado encontramos dificuldades em saber qual é o seu valor. Assim, emerge a seguinte questão: Como quantificar o valor econômico dos bens e serviços que são oferecidos pela natureza? Conforme o Fundo de Estratégia de Conservação (CSF,

\footnotetext{
${ }^{3}$ Estudo sobre a estrutura de Serviços Ecossistêmicos (SE) do Sudeste de Queensland (SEQ) Austrália (MAYNARD et al., 2010).

${ }^{4}$ Estimativa do valor econômico-ecológico da planície de inundação do Rio Araguaia e influência do público-alvo na valoração ambiental (ANGELO, 2010); Valoração econômica e percepção ambiental da área de proteção ambiental estadual cachoeira das andorinhas - sub-bacia do Rio das Velhas (SILVEIRA, 2011); Valorização ambiental: proposição do método de valorização para Estação Ecológica Maracá-Jipióca. (CORRÊA e FERREIRA, 2013); entre outros.
} 
da sigla em inglês Conservation Strategy Fund, 2018) uma vez que pudermos quantificar esses benefícios correlacionando-os aos aspectos de nossas vidas, nosso poder decisório poderá escolher os melhores resultados para a gestão desses recursos.

Além disso, o valor estimado dos SEs pode constituir uma forma de avaliar as perdas do bem-estar da população quando ameaçadas pelos impactos negativos ocasionados pelos usos indevidos e pelas atividades humanas desordenadas. $O$ conhecimento sobre o valor econômico dos recursos naturais por meio de métodos de valoração surge como alternativa para gestão de áreas protegidas. Ao aplicar este conhecimento na gestão de uma unidade de conservação pode-se levar a um aumento da arrecadação de recursos financeiros para a unidade, possibilitando, por exemplo, o aumento do número de funcionários, compra e manutenção de equipamentos e veículos de fiscalização e investimentos em projetos de educação ambiental com a comunidade do entorno (SILVEIRA, 2011).

É dentro desse contexto que esta pesquisa, a partir de um recorte espacial, utilizando a Unidade de Conservação Parque Natural Municipal Lagoa do Jacaré das Dunas do Santinho (PNMLJ), localizado na Praia do Santinho, no extremo nordeste da Ilha de Santa Catarina (ISC), Florianópolis, SC, busca responder primeiramente: Quais são os serviços ecossistêmicos e quais os benefícios que os ecossistemas da Zona Costeira nos proporcionam? E, em segundo momento: Qual o valor que pagaríamos pelo uso desses serviços se eles nos fossem cobrados?

A escolha do PNMLJ se deve, primeiramente, por ele estar situado na Zona Costeira, pela diversidade dos seus ecossistemas naturais, pela importância dos seus SEs para o bem-estar da população local, enfatizando o manancial de água doce subterrânea para o abastecimento público do nordeste da llha de Santa Catarina e, por ser uma Unidade de Conservação recém-criada sob a pressão do avanço imobiliário na região. Além disso, o local está situado entre a Praia dos Ingleses e a Praia do Santinho, importantes balneários que fomentam a economia do turismo de Florianópolis. Fatos esses que corroboram para responder os questionamentos levantados por esta pesquisa.

Entretanto, com a ausência de um valor de mercado para os serviços ecossistêmicos, o estabelecimento de um preço ou de um valor monetário para os benefícios oriundos desses serviços fica prejudicado (SILVA, 2003). Uma das soluções utilizadas para suprir essa dificuldade é a implantação de métodos de valoração ambiental, que captam e atribuem valores para os bens e serviços 
gerados pelo meio ambiente (FINCO \& ADBDALLAH, 2002). Esses métodos de valoração podem ainda quantificar monetariamente os impactos econômicos e sociais de projetos cujos resultados numéricos vão permitir uma avaliação mais abrangente (HUFSCHMIDT et al. 1983 apud FONSECA et al., 2013).

É importante destacar que o termo "valoração econômica ecossistêmica" provém da quantificação, em termos monetários, dos serviços que os ecossistemas fornecem para o bem-estar humano. Devido à cronologia e as diferentes disciplinas (economia, biologia, entre outras) que estudam essa valoração, nos deparamos com diversas expressões utilizadas nos estudos aqui referenciados, como: valoração dos recursos ambientais, valoração econômica ambiental, valoração econômica do meio ambiente, etc. Contudo, seus significados são similares e nesta pesquisa, representam o valor econômico de um serviço ecossistêmico.

Embora não haja uma classificação universalmente aceita sobre as técnicas de valoração econômica ecossistêmica (FONSECA et al., 2013), existem diferentes métodos que são utilizados para valorar um serviço ecossistêmico ou um bem específico. Entre os principais estão: Método de Valoração Contingente (MVC), Preços Hedônicos (MPH), Custo de Viagem (MCV), Produtividade Marginal (MPM) ou Dose-Resposta (MDR), Mercado de Bens Substitutos (MBS), Custos Evitados (MCE), Custos de Controle (MCC), Custo de Reposição (MCR), Custos de Oportunidade (MCO) e Método Baseado no Mercado (MBM).

Neste trabalho tratou-se de valorar economicamente os SEs Culturais relacionados ao lazer e à recreação. Para isso o Método do Custo de Viagem (MCV) foi considerado o mais apropriado.

O conceito do MCV é que os gastos efetuados pelas famílias para se deslocarem a um lugar, geralmente para recreação, podem ser utilizados como uma aproximação dos benefícios proporcionados por essa recreação. A aplicação desse método geralmente é restrita à valoração de características peculiares aos locais (geralmente lugares de recreação) e à valoração do tempo (PEARCE, 1993 apud FONSECA et al., 2013). Os dados são obtidos por meio de questionários aplicados a uma amostra da população no local de visitação (FONSECA et al., 2013).

Assim, este trabalho identificou os ecossistemas costeiros existentes no PNMLJ, suas funções e os seus SEs Culturais de recreação e lazer, assim como, os seus respectivos benefícios. Com a definição dos SEs culturais mais relevantes, foi possível aplicar o método de valoração econômica do Custo de Viagem (MCV), 
identificar o valor econômico dos SEs e demonstrar a importância da regulação do seu uso, assim como, a conservação dos ecossistemas costeiros.

\section{Métodos}

\section{- Área de estudo}

O recorte espacial desta pesquisa é a Unidade de Conservação Parque Natural Municipal Lagoa do Jacaré das Dunas do Santinho (PNMLJ), localizada entre a Praia dos Ingleses e a Praia do Santinho, importantes balneários turísticos, no extremo nordeste da llha de Santa Catarina (ISC). A área legal do PNMLJ possui uma superfície de 221,07 ha (PMF, 2016), sob as coordenadas $27^{\circ} 25^{\prime} 52.32^{\prime \prime} \mathrm{S}$ e $48^{\circ} 21^{\prime} 28.55^{\prime \prime}$ Latitude Norte, e, $27^{\circ} 27^{\prime} 56.53^{\prime \prime} S$ e $48^{\circ} 22^{\prime} 49.55^{\prime \prime}$ Latitude Sul (Datum: WGS84) (Erro! Fonte de referência não encontrada.). O PNMLJ é delimitado ao norte pelo canto direito da Praia dos Ingleses, a leste pela Praia do Santinho, ao sul pelo Morro das Aranhas e, a oeste pelo setor urbanizado da Praia.

Os limites do PNMLJ tiveram como base os vértices georreferenciados da poligonal que define o limite indicado para a unidade de conservação, dispostos no Memorial descritivo, no Anexo I, da Lei 9.948/2016 conforme a PMF (2016).

Figura 1- Localização do PNMLJ 


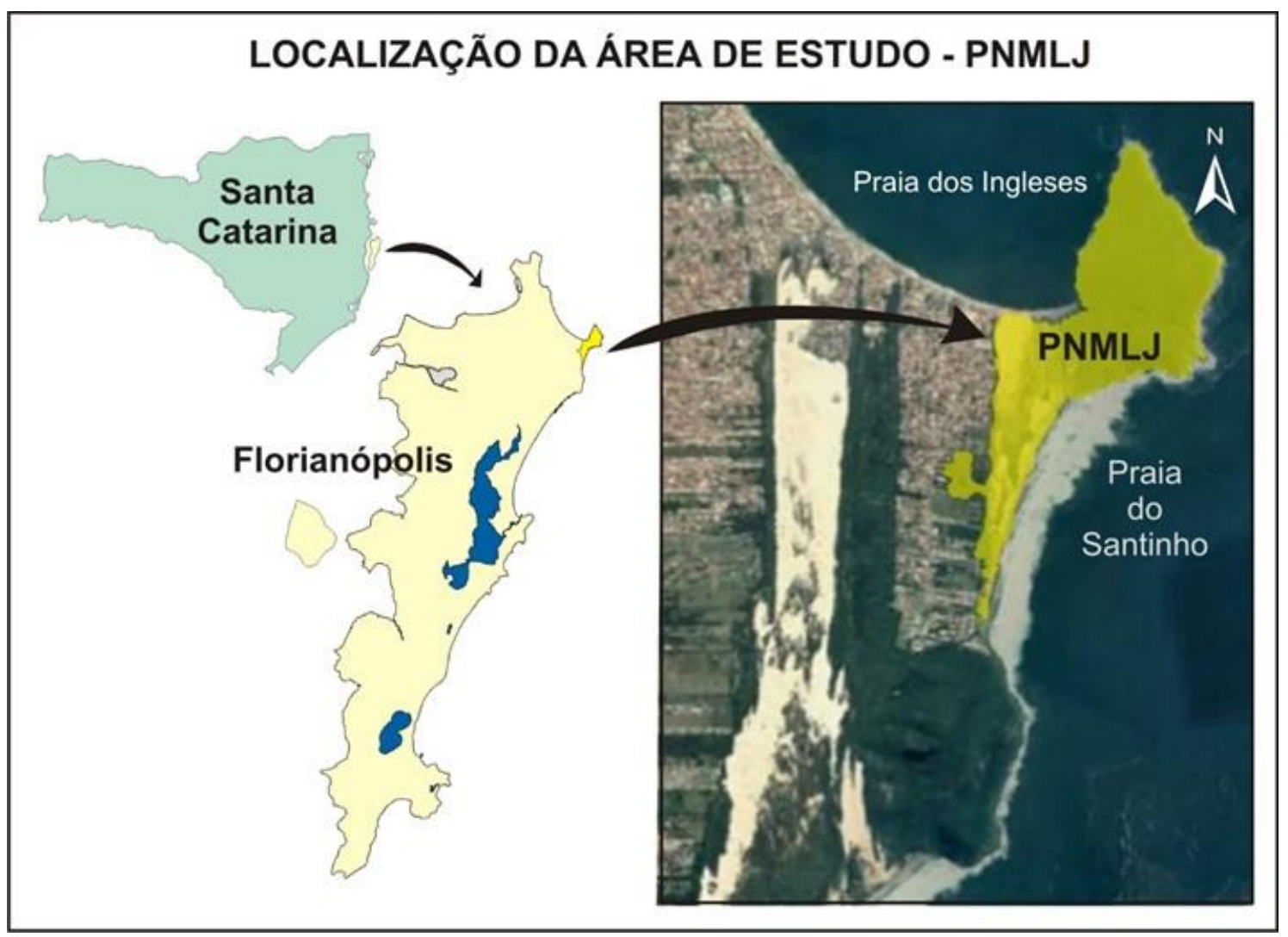

Elaboração: Otelino Nunes da Silva

\section{- Cálculo das áreas dos ecossistemas do PNMLJ}

Para a análise dos ecossistemas do PNMLJ, cálculo das áreas e confecção do Mapa de Ecossistemas da UC PNMLJ foi utilizado um Sistema de Informações Geográficas (SIG) na plataforma ArcGIS. Os shapes utilizados foram obtidos de Lima et al. $(2018)^{5}$ que mapearam os ecossistemas da Ilha de Santa Catarina utilizando o software QGIS 2.18.9 por meio de fotointerpretação e vetorização dos ecossistemas com base nas ortofotos da SDS (2010). As informações altimétricas foram obtidas em Modelo Digital de Terreno (MDT) pelo (SDS, 2010). As formações geológicas tiveram como base o mapeamento de Tomazzoli \& Pellerin (2015). A cobertura vegetal foi baseada nos dados não publicados, cedidos pela Gerência de Cartografia do Instituto de Planejamento Urbano de Florianópolis. A geometria básica dos ecossistemas foi obtida em escala fixa de 1:25.000. No entanto, Lima et al. (2018) refinou a base cartográfica apoiado em mapeamentos de diversas escalas e resoluções espaciais, sobretudo de maior precisão.

O ecossistema praial, apesar de não ser mapeado oficialmente na área do PNMLJ, foi escopo deste estudo. Isso porque ele bordeja toda a porção leste do

${ }^{5}$ Informação de Base Ecossistêmica como Ferramenta de Apoio à Gestão Costeira Integrada da Ilha de Santa Catarina. 
Parque e tem relação direta com a intervenção antrópica que incide sobre seu interior (e.g.: acesso ao turismo, a pesca, ao lazer, a recreação, entre outros).

A delimitação do ecossistema praial foi feita por meio de interpretação do conceito de Suguio (1992) que estabelece a praia como sendo a área que se estende da face praial (zona de arrebentação) até o pós-praia (vegetação de restinga, costão rochoso, duna frontal, etc.).

A partir desse conceito, da imagem do satélite Constellation Optique 3D da Air Bus, de 19/05/2018, com resolução de $50 \mathrm{~cm}$, obtida no aplicativo Google Earth, e de fotografias da morfologia praial, se delimitou a borda oeste do pós-praia, pela divisa com a berma e/ou escarpa praial, costão rochoso e/ou a vegetação de restinga. O limite da praia, a leste, denominada de face praial, foi delimitado pela linha média da zona de arrebentação. As fotos foram realizadas em uma saída de campo no dia 27/05/2018, utilizando uma câmera fotográfica Sony Cyber Shot, posicionada sobre um tripé.

\section{- Definição dos serviços ecossistêmicos (SEs) do PNMLJ}

Como descrito anteriormente na Introdução deste artigo, os serviços ecossistêmicos (SEs) são produzidos através de uma complexa interação de processos, denominadas de funções ecossistêmicas (MAYNARD et al., 2010). Essas funções, de acordo com Costanza et al. (2017), apesar de contribuírem para os serviços ecossistêmicos não são sinônimos. Elas descrevem as relações biofísicas que existem independentemente de beneficiar ou não os seres humanos. Em contrapartida, os SEs são aqueles processos que beneficiam as pessoas, consciente ou inconscientemente, direta ou indiretamente.

Neste estudo, a classificação das funções e serviços ecossistêmicos, benefícios e constituintes do bem-estar do PNMLJ, se baseou no estudo realizado por Maynard et al. (2010) para os Serviços Ecossistêmicos do Sudeste de Queensland (SEQ) (Austrália) (Quadro 1). No SEQ, foram levantados primeiramente os ecossistemas da região de estudo e, por conseguinte, sua função ecossistêmica, seus serviços ecossistêmicos e as constituintes do bem-estar humano. No caso desta pesquisa, em específico, diferente do SEQ, que empregou o termo "Relatório de Categorias de Ecossistema" para agrupar 176 ecossistemas regionais similares, se utilizou a nomenclatura e a classificação dos ecossistemas (e.g.: banhado, costão rochoso, duna, entre outros) conforme o estudo realizado por Lima et al. (2018), baseado em Scherer \& Asmus (2016). 
Quadro 1- Exemplo da estrutura utilizada para a classificação ecossistêmica

\begin{tabular}{|l|l|l|l|l|}
\hline ECOSSISTEMAS: & \multicolumn{4}{|l|}{ Fonstituinte do } \\
\hline Categoria & $\begin{array}{l}\text { Função } \\
\text { ecossistêmica }\end{array}$ & $\begin{array}{l}\text { Serviço } \\
\text { ecossistêmico }\end{array}$ & Benefício & \begin{tabular}{l} 
bem-estar \\
\hline
\end{tabular} \\
\hline
\end{tabular}

Somado aos ecossistemas, outros dois itens, denominados de PNMLJ, foram incluídos na classificação. O primeiro tratou de abranger todos os SEs Culturais relacionados à Educação, ao Patrimônio Cultural, Existência e Legado, que não foram abordados diretamente pelos ecossistemas do PNMLJ, mas que são oriundos da existência desses. E, o segundo e mais importante para a valoração econômica ecossistêmica do PNMLJ pelo Método do Custo de Viagem, escopo principal deste artigo, apresentado no tópico a seguir, tratou de agrupar os SEs Culturais de Recreação e Lazer provenientes diretamente de todos os ecossistemas do Parque.

Em relação ao bem-estar humano, a MEA (2005) coloca esse item no foco central da avaliação, argumentando que ele, associado à provisão de serviços ecossistêmicos, é determinado por vários constituintes: Materiais básicos para um meio de vida viável (E); Boa saúde $(H)$; Boas relações socioculturais (GSR); Segurança (S); e, Liberdade de escolha e ação (FCA).

Nesse contexto, para a identificação dos SEs do PNMLJ, primeiramente se identificou, por meio de informações empíricas, ou seja, pela observação, os benefícios e as constituintes do bem-estar gerados à população local pela existência dos ecossistemas do PNMLJ. Posteriormente, esses dados foram analisados frente às classificações elaboradas por Costanza et al. (1997), MEA (2005), Maynard et al. (2010) e ratificados por meio das respostas dos questionários ${ }^{6}$, aplicados pelo Método do Custo de Viagem (MCV) aos turistas que visitam a região. Além disso, nos resultados da classificação ecossistêmica do PNMLJ foram inseridas informações complementares provenientes da Classificação Internacional de Serviços Ecossistêmico (CICES) (versão 5.1).

\section{- Aplicação do Método do Custo de Viagem (MCV)}

O MCV estabelece uma função relacionando a taxa de visitação às variáveis de custo de viagem, tempo, taxa de entrada, características socioeconômicas do visitante, e outras variáveis que possam explicar a visita a um patrimônio natural ou a um lugar de uso recreativo. Os dados são obtidos por meio de questionários

\footnotetext{
${ }^{6}$ A estruturação dos questionários é apresentada no item 4 da Aplicação do Método do Custo de Viagem.
} 
aplicados a uma amostra da população no local de visitação (FONSECA et al., 2013).

Os dados obtidos através dos questionários foram tabulados e analisados em planilhas EXCEL ${ }^{\circledR}$, software do pacote Microsoft Office ${ }^{\circledR}$ 2010. Para a análise qualitativa das questões abertas se utilizou o processo de categorização e, para a análise dos resultados das questões fechadas, a quantificação por meio de percentuais e cruzamento de dados.

Para desenvolvimento dos questionários foram seguidos os seguintes passos:

1) Definição do local de amostragem: área do PNMLJ e o ecossistema praial.

2) Definição do tamanho da população: devido à falta de informações da Secretaria Municipal de Turismo de Florianópolis (SETUR) sobre o local, buscou-se os dados da rede hoteleira da localidade do Santinho. As informações foram extraídas do estudo de Pires (2015), a qual analisou o Costão do Santinho Resort, Golf \& Spa (Costão do Santinho), maior hotel/resort do local. O tamanho da população foi definido como sendo a média do número de turistas que se hospedaram no hotel/resort entre os anos de 2010 e 2014. Considerou-se apenas os turistas que vieram para o local com o intuito de lazer. A média anual de visitantes foi de 159.573 pessoas.

3) Definição da amostra: utilizou-se o cálculo amostral a partir da seguinte fórmula.

Fórmula: $\mathbf{F 1} \quad n=\underline{Z^{2} \times p \times(1-p)}$

$$
e^{2}
$$

Sendo:

$n$ : tamanho da amostra que irá se calcular

$N$ : tamanho da população a ser estudada $=159.573$

e: margem de erro que irá se admitir $=(17 \%) \mathbf{0 , 1 7}$

p: proporção á se encontrar $=(50 \%)$ 0,5

$z$ : escore $Z$ = (para 95\% de confiança) $\mathbf{1 , 9 6}$

Cálculos: $\mathbf{F 1} \quad \mathrm{n}=1,96^{2} \times 0,5 \times(1-0,5) / 0,17^{2}=33,23183$ ou 33

O número amostral foi definido como 33 turistas a serem entrevistados. 
De acordo com Ochoa (2018) a margem de erro (e) é o intervalo no qual se espera encontrar o dado que se quer medir no universo (população). $O$ dado pode ser em geral de dois tipos: uma média ou uma proporção. No caso dessa pesquisa utilizou-se a proporção. Ou seja, para estimar o número de turistas que visitariam o PNMLJ, a partir de um número de 159.573 turistas, considerando uma margem de erro de 17\%, identificou-se um número compreendido entre 186.700 e 132.446 turistas.

O nível de confiança ( $z$ ) expressa a certeza de que o dado que se buscou está dentro da margem de erro. Isto é, com base na pesquisa, utilizando-se um nível de confiança de $95 \%$, infere-se que a porcentagem de turistas do meu universo que visitariam o PNMLJ, em 95\% dos casos se encontrará entre 186.700 e 132.446 turistas. Ou seja, conforme Ochoa (2018), se a pesquisa for repetida 100 vezes, selecionando amostras aleatórias do mesmo tamanho, 95 vezes a proporção que se busca estaria dentro do intervalo de 186.700 e 132.446 e 5 vezes fora dele. O nível de confiança de 95\% corresponde ao escore Z de 1,96. Esse índice, segundo Ochoa (2018) é determinado pela distribuição de Gauss.

Para Ochoa (2018) a razão pela qual a proporção $(p)$ aparece na fórmula é que quando uma população é muito uniforme (população de turistas), a convergência para uma população normal é mais precisa, permitindo-se reduzir o tamanho da amostra. No caso dessa pesquisa, como não se sabia o percentual (\%) de turistas que visitariam a área do PNMLJ, a opção mais prudente foi usar um cenário de precaução, ou seja, distribuir a população em partes iguais entre turistas que visitariam e turistas que não visitariam, $\log 0 p=50 \%$. No entanto, o resultado demonstrou que o total de entrevistados, isto é, $100 \%$ do total da amostra visitou a área do PNMLJ.

4) Estruturação do questionário aplicado aos turistas visitantes do PNMLJ: a pesquisa foi estruturada a partir de informações de outros questionários aplicados por Angelo (2010), Brant (2011), Silveira (2011) e Corrêa \& Ferreira (2013) com alterações das perguntas objetivando a tabulação de dados específicos para a aplicação do Método do Custo de Viagem (MCV) no PNMLJ.

Os questionários foram aplicados no período de janeiro a fevereiro de 2019 . Escolheu-se os dias ensolarados, sem vento, entre as 9:00 e 12:00 horas e das 15:00 as 18:00 horas, alternando-se dias da semana e finais de semana. As entrevistas foram feitas de forma aleatória na Praia do Santinho, observando-se apenas a disponibilidade dos entrevistados para responderem o questionário. 
A estruturação dos questionários e tabulação dos dados está disponível em: https://drive.google.com/drive/folders/12r-3Ch-kJEIQz4gj5de7kU3hv4hj_yiY

Os questionários foram divididos em 3 partes, sintetizadas a seguir:

$1^{a}$ ) Caracterização socioeconômica do entrevistado: Coleta de dados relativos a renda do entrevistado, local de origem, tempo e custo de transporte, custos de hospedagem, alimentação e outros gastos complementares, número de acompanhantes, e, dados relativos a sua preferência pelo local de destino de viagem.

$2^{a}$ ) Percepção ambiental dos turistas visitantes em relação ao PNMLJ: Coleta de dados referentes ao conhecimento do entrevistado em relação às Unidades de Conservação, em específico ao PNMLJ e seus serviços ecossistêmicos.

$3^{\text {a }}$ ) Indicadores de percepção ambiental geral dos turistas entrevistados: Coleta de dados sobre o entendimento do entrevistado quanto às questões relacionadas ao meio ambiente e das suas atitudes perante ele. Para cada questão foi aplicado um nível de variação de percepção ou importância. Atribui-se um grau de 1 a 5, no qual 1 indica que a pessoa dá baixa importância ou tem pouca percepção sobre o assunto, e 5, se o entrevistado dá muita importância ou tem alta percepção sobre a questão perguntada. Os indicadores tiveram como base o estudo de Silveira (2011).

Para cada pessoa entrevistada apresentou-se um mapa com a localização e a área do PNMLJ, fotos, texto explicativo e, um esclarecimento de quais são os benefícios ao bem estar da população fornecida pelos serviços ecossistêmicos do Parque. Além disso, foi lido um termo de consentimento, o qual explicita os motivos da pesquisa e informa que as respostas terão anonimato.

\section{- Estimativa da valoração econômica do uso do PNMLJ pelo MCV}

Neste estudo se utilizou o MCV individual que, segundo Motta (1997), considera os custos da viagem variando por indivíduos em relação ao local, sem agrupá-los por zonas, mas sim pelo local de sua origem. As variáveis utilizadas foram o custo do tempo de viagem, o custo do transporte e os custos diários com deslocamentos, alimentação e hospedagens.

A partir dos dados obtidos pelos questionários, se calculou os custos de viagem ao PNMLJ, e, por conseguinte, o valor estimado de seu uso, por meio dos seguintes procedimentos: 
$\left.1^{\circ}\right)$ Valor do custo do tempo de viagem: A variável tempo de viagem foi convertida em um valor monetário. Esse valor é relativo ao valor hora da renda que deixou de ser ganha com a viagem pelo entrevistado/motorista e multiplicado pelo número de horas de viagem de ida e volta. $O$ valor hora foi baseado na média da faixa de categoria de renda mensal informada na entrevista e dividido por 220 (número médio de horas trabalhadas em um mês).

Fórmula: $\quad$ 2 $\quad C t=R e x T t$

Sendo:

Ct: Custo do tempo de viagem de ida e volta entre o local de origem e o PNMLJ $R e:$ Renda média do entrevistado por hora ${ }^{7}$

Tt: Tempo médio de viagem de ida e volta entre o local de origem e o PNMLJ

$2^{\circ}$ ) Custo do transporte da viagem: É a soma dos custos com o transporte (combustível, pedágio, táxi, uber, revisão do carro, pneus, entre outros) necessários para o entrevistado chegar ao PNMLJ e para retornar ao seu local de origem.

Sendo:

Cv: Custo do transporte da viagem de ida e volta entre o local de origem e o PNMLJ

$3^{\circ}$ ) Valor diário com transporte e alimentação: É a soma dos custos diários que o entrevistado teve com transporte e alimentação durante sua estadia.

Sendo:

$P$ : Valor diário gasto com transporte e alimentação

$4^{\circ}$ ) Valor diário de hospedagem: É a soma de todos os custos diários com hospedagem (hotel, pousadas aluguel de casas ou apartamentos, ajuda de custo em casa de amigos ou familiares).

Sendo:

G: Valor diário de hospedagem

7 O valor hora foi baseado na média da faixa de categoria de renda mensal informada na entrevista e dividido por 220 (número médio de horas trabalhadas em um mês no Brasil). 
$5^{\circ}$ ) Valor do custo total da viagem: De posse dos dados calculados pelas fórmulas acima e do valor diário de hospedagem e do número de dias de hospedagem gastos pelo turista se obteve o valor do custo total da viagem.

Fórmula: $\quad$ F3 $\quad v v=(G \times D)+(P \times D)+C v+C t$

Sendo:

$V v$ : Custo total da viagem de ida e volta entre o local de origem e o PNMLJ

G: Valor diário de hospedagem

$D: \mathrm{n}^{\circ}$ de dias de hospedagem

$P$ : Valor diário com transporte e alimentação

Cv: Custo do transporte da viagem de ida e volta entre o local de origem e o PNMLJ $C t$ : Custo do tempo de viagem de ida e volta entre o local de origem e o PNMLJ

$6^{\circ}$ ) Valor médio diário gasto por visitantes ao PNMLJ: É o custo total da viagem de cada turista entrevistado dividido, primeiramente, pelo número de dias de hospedagem, e em seguida, dividido pelo número total de visitantes acompanhantes do entrevistado, incluindo esse.

Fórmula: $\quad \mathbf{F 4} \quad V m=(V V / D) / T$

Sendo:

$V m$ : Valor médio diário gasto por visitantes ao PNMLJ

$V v$ : Custo total da viagem de ida e volta entre o local de origem e o PNMLJ

$D: n^{\circ}$ de dias de hospedagem

$T: n^{\circ}$ total de visitantes acompanhantes do entrevistado, incluindo esse.

$7^{\circ}$ ) Valor estimado de Uso diário do PNMLJ: É a soma dos valores médios diários gastos por todos os visitantes divididos pelo número total de entrevistados da amostra de pesquisa.

Fórmula: $\quad$ F5 $\quad V d=\left(V m_{1}+V m_{2}+V m_{3}+\ldots+V m_{33}\right) / T e$

Sendo:

Vd: Valor estimado de Uso diário do PNMLJ

$V m_{1,2, \ldots, 33:}$ Valor médio diário gasto por todos os visitantes (soma dos 33 valores)

Te: Número total de entrevistados na amostra $=\mathbf{3 3}$ 
$8^{\circ}$ ) Valor estimado de Uso Anual do PNMLJ: É o valor estimado de uso diário do PNMLJ multiplicado pelo número estimado de turistas que frequentam a área do PNMLJ ao ano.

Fórmula: $\quad \mathbf{F 6} \quad V U=V d \times T T$

Sendo:

VU: Valor estimado de Uso Anual do PNMLJ

Vd: Valor estimado de Uso diário do PNMLJ

TT: Número de turistas que freqüentaram a área do PNMLJ por ano

\section{Resultados}

- Áreas dos ecossistemas do PNMLJ

A partir da delimitação da área de estudo e identificação dos seus ecossistemas, foi possível elaborar um quadro de áreas (Tabela 1) e o Mapa de Ecossistemas da Unidade de Conservação PNMLJ apresentado na Erro! Fonte de referência não encontrada..

Tabela 1- Ecossistemas naturais do PNMLJ e suas respectivas áreas

\begin{tabular}{l|r|r|r|c|}
\hline Ecossistema/Uso do solo & Perímetro $\mathbf{( m )}$ & \multicolumn{1}{c|}{ Área $\left.\mathbf{( m}^{\mathbf{2}}\right)$} & Hectares & \multicolumn{1}{c|}{$\%$} \\
\hline Urbano & $1.032,41$ & $15.561,30$ & 1,56 & 0,70 \\
\hline Reflorestamento & 178,16 & 539,40 & 0,05 & 0,02 \\
\hline Subtotal & $1.210,56$ & $16.100,70$ & 1,61 & 0,72 \\
\hline Banhado & $1.785,70$ & $49.744,47$ & 4,97 & 2,25 \\
\hline Costão rochoso & $9.128,31$ & $112.629,76$ & 11,26 & 5,09 \\
\hline Duna & $11.605,76$ & $313.236,40$ & 31,32 & 14,17 \\
\hline Restinga & $14.822,64$ & $540.918,25$ & 54,09 & 24,47 \\
\hline Mata Atlântica & $7.155,15$ & $1.178 .114,09$ & 117,81 & 53,29 \\
\hline Total 1 & $\mathbf{4 5 . 7 0 8 , 1 2}$ & $\mathbf{2 . 2 1 0 . 7 4 3 , 6 7}$ & $\mathbf{2 2 1 , 0 7}$ & $\mathbf{1 0 0 , 0 0}$ \\
\hline Praia (porção leste) & $5.964,56$ & $1.195 .729,40$ & 119,57 & - \\
\hline Total (Total 1 + Praia) & $\mathbf{5 1 . 6 7 2 , 6 8}$ & $\mathbf{3 . 4 0 6 . 4 7 3 , 0 7}$ & $\mathbf{3 4 0 , 6 3}$ & - \\
\hline
\end{tabular}


Figura 2- Localização e distribuição dos ecossistemas na área do PNMLJ. Elaborado a partir de PMF (2016), Lima et al. (2018) e Google Earth (2018)

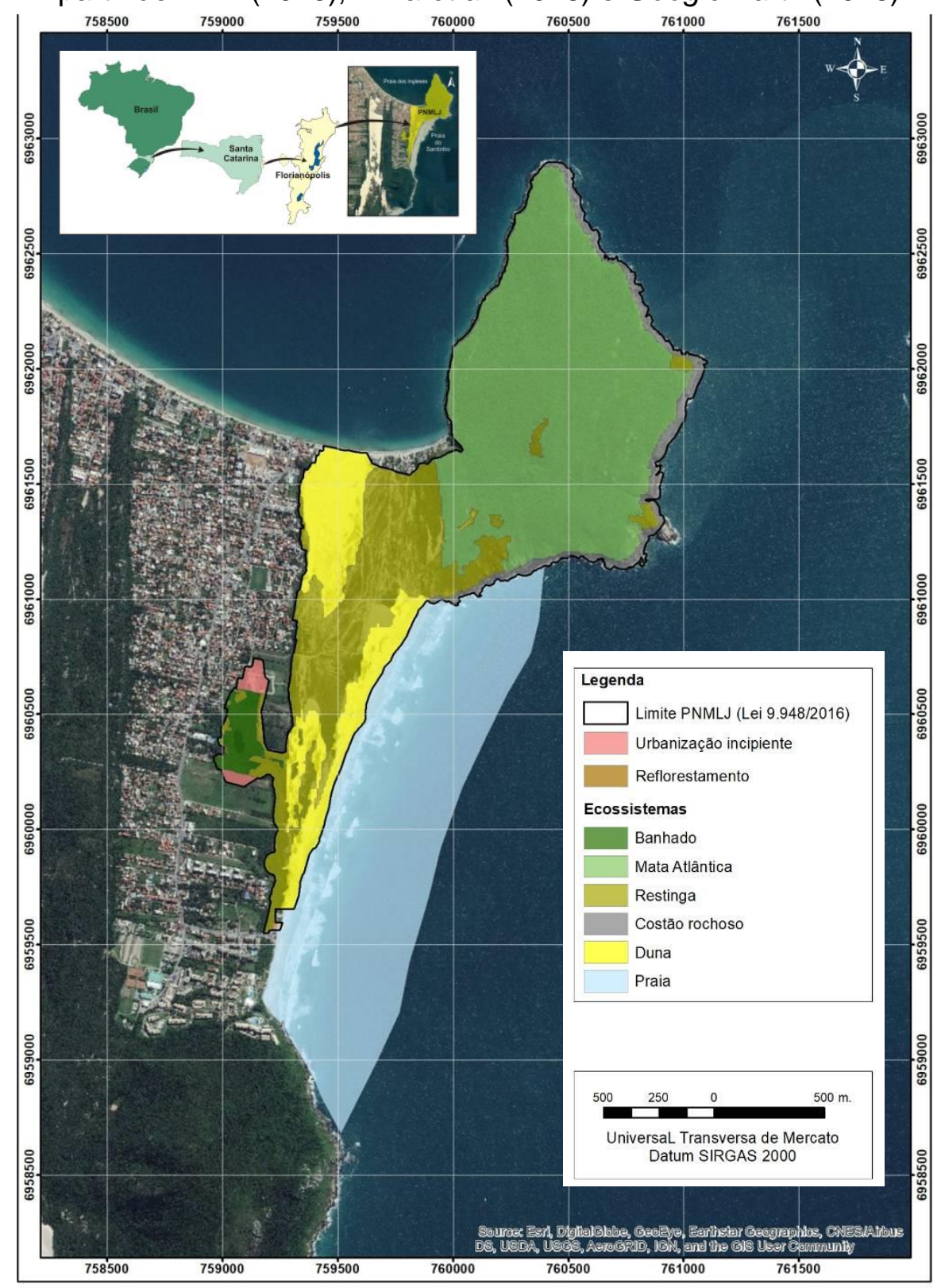

No total foram mapeados, dentro da área legal do PNMLJ, cinco ecossistemas naturais (Banhado, Costão Rochoso, Duna, Restinga e Mata Atlântica) e dois sistemas representativos de uso do solo (Urbano e Reflorestamento). Além desses, apesar de não estar associado à área do Parque, o ecossistema Praial foi escopo 
deste estudo, e dessa forma, integrado ao PNMLJ. Sua relação direta com a intervenção antrópica (e.g.: acesso ao turismo, a pesca, ao lazer, a recreação, entre outros) que incide sobre o interior do Parque foi o principal motivo para a tomada dessa decisão.

A área legal do PNMLJ apresenta 221,07ha, compreendida por 53,29\% de Mata Atlântica, 24,47\% de Restinga, 14,17\% de Duna, 5,09\% de Costão rochoso, $2,25 \%$ de Banhado e $0,72 \%$ de uso antrópico. Somado a essa, a área de 119,57ha do ecossistema praial totalizou 340,63ha de área de estudo (Tabela 1)

\section{- Serviços ecossistêmicos do PNMLJ}

Ao todo foram identificados 20 serviços ecossistêmicos ${ }^{8}$, sendo: 4 de Provisão, seguidos por 5 de Regulação e Manutenção; e, 11 Culturais. Desses últimos, 6 foram escolhidos para valorar economicamente o uso dos SEs Culturais do PNMLJ pelo Método do Custo de Viagem (Quadro ). Isso se deu, primeiro, por esses seis SEs apresentarem características relacionadas ao lazer e a recreação, atributos esses, importantes para a escolha de um local de veraneio pelos turistas. Em segundo momento, por serem SEs relevantes para a economia do turismo da região, e com isso, poderem sofrer com os impactos negativos decorrentes dessa atividade. Enfim, por serem representativos dos vários ecossistemas existentes no PNMLJ, e dessa forma, chamar a atenção para a importância da conservação dos ecossistemas costeiros e, também das Unidades de Conservação (UCs).

Os outros 5 SEs Culturais relacionados a Educação, ao Patrimônio cultural, Existência e Legado, assim como os demais SEs de Provisão e Regulação e Manutenção foram escopo de outros métodos de valoração econômica, não contemplados neste artigo, mas que podem ser conferidos na íntegra na dissertação de mestrado 9 do autor.

Quadro 2- Classificação ecossistêmica dos SEs Culturais, de recreação e lazer do PNMLJ valorados pelo MCV

\begin{tabular}{|c|c|c|c|c|c|c|}
\hline \multicolumn{2}{|c|}{ Funções ecossistêmicas } & Serviços ecossistêmicos & Bens e benefícios & \multicolumn{3}{|c|}{ Constituintes do bem-estar } \\
\hline $\begin{array}{l}\text { Interações físicas } \\
\text { experienciais com } \\
\text { ambiente natural }\end{array}$ & $\begin{array}{l}\text { e } \\
\text { o }\end{array}$ & $\begin{array}{l}\text { Possuir } \\
\text { ecológicas (trilhas pela } \\
\text { floresta e pelo ambiente } \\
\text { dunar e praial), geológicas } \\
\text { (ambiente íngreme e }\end{array}$ & $\begin{array}{l}\text { Oportunizar a prática } \\
\text { recreativa e esportiva ao ar } \\
\text { livre para melhorar o } \\
\text { condicionamento físico e } \\
\text { mental (rústicas, }\end{array}$ & $\begin{array}{l}\text { Boas } \\
\text { (GSR) }\end{array}$ & Relações & Sociais \\
\hline
\end{tabular}

\footnotetext{
${ }^{8}$ A classificação ecossistêmica completa do PNMLJ está disponível em https://drive.google.com/drive/folders/12r-3Ch-kJEIQz4gj5de7kU3hv4hj_yiY?usp=sharing

9 SILVA, Otelino Nunes da. Valoração Econômica dos Serviços Ecossistêmicos da Zona Costeira.

Dissertação de Mestrado. Universidade Federal de Santa Catarina, CFH, Florianópolis, 2019. 255p.
} 


\begin{tabular}{|c|c|c|c|}
\hline Funções ecossistêmicas & Serviços ecossistêmicos & Bens e benefícios & Constituintes do bem-estar \\
\hline & $\begin{array}{l}\text { rochoso), que } \quad \text { tornam } \\
\text { atraente as atividades } \\
\text { recreativas }\end{array}$ & $\begin{array}{l}\text { caminhadas, Yoga, sand } \\
\text { board, voo livre, } \\
\text { aeromodelismo, escalada, } \\
\text { ecoturismo, descanso, pesca } \\
\text { esportiva, pesca artesanal, } \\
\text { surfe, passeios de } \\
\text { quadriciclos, entre outros). }\end{array}$ & Saúde Física $(\mathrm{H})$ \\
\hline $\begin{array}{lrr}\text { Interações } & \text { físicas } & \text { e } \\
\text { experienciais } & \text { com } & 0 \\
\text { ambiente natural. } & & \end{array}$ & $\begin{array}{l}\text { Possuir qualidades } \\
\text { ecológicas que proporcionam } \\
\text { a combinação de uma } \\
\text { variedade de espécies da } \\
\text { vida selvagem. }\end{array}$ & $\begin{array}{l}\text { Oportunizar a visitação para } \\
\text { a observação e identificação } \\
\text { de pássaros e animais } \\
\text { silvestres. }\end{array}$ & $\begin{array}{l}\begin{array}{l}\text { Boas Relações Sociais } \\
\text { (GSR) }\end{array} \\
\text { Saúde Física }(H) \\
\text { Saúde mental }(H)\end{array}$ \\
\hline $\begin{array}{l}\text { Interações intelectuais e } \\
\text { representativas com o meio } \\
\text { ambiente natural. }\end{array}$ & $\begin{array}{l}\text { Possuir características } \\
\text { físicas e ecológicas que } \\
\text { proporcionam ao lugar um } \\
\text { local especial para estudo } \\
\text { científicorason } \\
\text { formações vegetais, solo, } \\
\text { relevo e habitat de animais } \\
\text { distintos). }\end{array}$ & 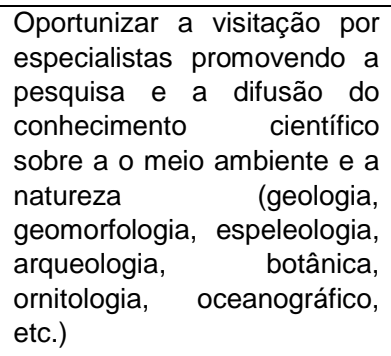 & Saúde mental $(\mathrm{H})$ \\
\hline $\begin{array}{l}\text { Interações intelectuais e } \\
\text { representativas com o meio } \\
\text { ambiente natural. }\end{array}$ & $\begin{array}{l}\text { Proporcionar a inspiração } \\
\text { artística por meio da } \\
\text { paisagem icônica (elevações } \\
\text { e cordões dunares, boulders, } \\
\text { cavernas e fendas, praia, } \\
\text { mar, vegetação, morros, etc.) }\end{array}$ & $\begin{array}{l}\text { Oportunizar a prática de } \\
\text { atividades inspiradoras, } \\
\text { artísticas e contemplativas } \\
\text { da natureza para } \\
\text { desestressar (fotografia, } \\
\text { pintura, caminhada, yoga, } \\
\text { meditação, etc.) }\end{array}$ & $\begin{array}{l}\text { Boas Relações Sociais } \\
\text { (GSR) }\end{array}$ \\
\hline 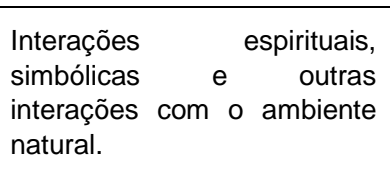 & $\begin{array}{l}\text { Possuir oficinas líticas e } \\
\text { inscrições (upestres } \\
\text { simbólicas (petroglifos) com } \\
\text { datas que variam de mil a } \\
\text { quatro mil anos }\end{array}$ & $\begin{array}{l}\text { Oportunizar a visitação } \\
\text { pública para o conhecimento } \\
\text { cultural da história dos } \\
\text { sambaquis de idade pré- } \\
\text { colombiana. }\end{array}$ & $\begin{array}{l}\text { Boas Relações Sociais } \\
\text { (GSR) } \\
\text { Saúde mental }(\mathrm{H})\end{array}$ \\
\hline 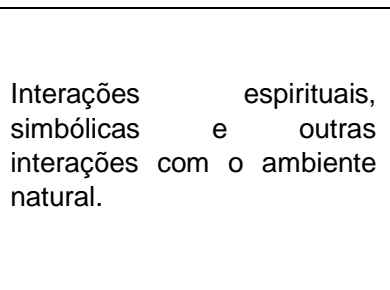 & $\begin{array}{l}\text { Possuir formação rochosa e } \\
\text { inscrições rupestres com } \\
\text { características físicas que } \\
\text { proporcionam ao imaginário } \\
\text { das pessoas criarem lendas } \\
\text { folclóricas. }\end{array}$ & $\begin{array}{l}\text { Promover o imaginário- } \\
\text { acoriano (Lenda do pé de } \\
\text { gigante moldado na rocha; } \\
\text { local onde estava um } \\
\text { petroglifo - figura com uma } \\
\text { auréola - que deu origem ao } \\
\text { nome da Praia do Santinho, } \\
\text { etc.). }\end{array}$ & Saúde mental $(\mathrm{H})$ \\
\hline
\end{tabular}

\section{- Resultados das entrevistas ${ }^{10}$}

$\left.1^{\circ}\right)$ Caracterização socioeconômica do entrevistado: No que diz respeito à renda mensal per capita, $28 \%$ dos entrevistados apresentou renda pessoal entre 5 a 10 salários mínimos ( $\mathrm{R} \$ 4.770,00$ a $\mathrm{R} \$ 9.540,00)$, seguido por $21 \%$ com renda de 3 a 5 salários, $15 \%$ de 1 a 2 e $12 \%$ de 2 a 3 salários. A renda de 10 a 20 salários representou $6 \%$ dos entrevistados, assim como os Sem renda e os que Não

\footnotetext{
${ }^{10}$ Os dados completos relativos às entrevistas (dados socioeconômicos e percepção ambiental, assim como o questionário e sua tabulação está disponível em: https://drive.google.com/drive/folders/12r3Ch-kJEIQz4gj5de7kU3hv4hj_yiY?usp=sharing
} 
responderam. Os que possuíam renda de $1 / 2$ a 1 salário e os que Não souberam informar representaram 3\% respectivamente.

Analisando a cidade de origem, 63\% dos turistas entrevistados são brasileiros e 37\% argentinos. A Unidade Federativa (UF) de maior procedência foi o Rio Grande do Sul (27\%), seguido pelo Paraná (21\%), Santa Catarina (9\%), Rio de Janeiro (3\%) e Mato Grosso do Sul (3\%).

$2^{\circ}$ ) Percepção ambiental dos turistas visitantes em relação ao PNMLJ: Os entrevistados, quando perguntados sobre se sabiam o que são os SEs, $85 \%$ respondeu desconhecer o assunto. No entanto, após serem informados que os SEs são os serviços que a natureza presta para a sociedade, tomando como exemplo alguns SEs do Parque, os turistas responderam, em sua opinião, qual deles era o mais importante. Mais da metade dos entrevistados (54\%) informou ser a paisagem de notável beleza cênica. A disponibilidade da água em forma de um aquífero foi o segundo (43\%). O terceiro foi a recreação, o lazer e o esporte (3\%).

Quando interpelados se suas atitudes poderiam afetar o PNMLJ negativa ou positivamente, $18 \%$ dos turistas informou que não e $82 \%$ dos turistas informou que sim. Esses últimos, apontaram 5 atitudes negativas, destacando o estacionamento do carro na área do Parque como sendo o principal (64\%). Também listaram 4 atitudes positivas. A mais referida foi a de levar o seu próprio lixo embora (33\%), seguido por recolher o lixo encontrado no chão (27\%), preservar o parque $(23 \%)$ e chegar a praia a pé, sem o uso de veículos automotores (17\%).

$3^{\circ}$ Indicadores de percepção ambiental geral dos turistas entrevistados: Outro ponto a ser somado ao perfil dos turistas que frequentam a área do PNMLJ foi o de possuírem conhecimento sobre o ambiente que frequentam e dos impactos de suas atitudes sobre esse. Os turistas entrevistados atribuíram nível máximo de importância em 72,45\% das 11 questões propostas sobre percepção ambiental.

\section{- Valor de uso do PNMLJ pelo MCV}

Os resultados da aplicação das fórmulas, apresentadas na metodologia da "Estimativa da valoração econômica do uso do PNMLJ pelo MCV", é apresentado na (Tabela 2) para cada um dos 33 turistas entrevistados. 
Tabela 2- Resultados do valor médio diário gasto por turistas ao PNMLJ

\begin{tabular}{|c|c|c|c|c|c|c|c|c|c|c|c|}
\hline No & $R m$ & $\boldsymbol{R e}$ & $T t^{*}$ & $C t$ & $G$ & $D$ & $P$ & $\mathrm{Cv}$ & $V v$ & $T$ & $V m$ \\
\hline 1 & $3.816,00$ & 17,35 & 1,6 & 27,75 & 0 & 2 & 150 & 40 & 367,75 & 2 & 91,94 \\
\hline 2 & $1.431,00$ & 6,5 & 34,4 & 223,76 & 0 & 4 & 75 & $1.000,00$ & $1.523,76$ & 2 & 190,47 \\
\hline 3 & $7.155,00$ & 32,52 & 11,16 & 362,95 & 0 & 15 & 80 & 300 & $1.862,95$ & 1 & 124,2 \\
\hline 4 & $2.385,00$ & 10,84 & 18,76 & 203,38 & 250 & 4 & 275 & 900 & $3.203,38$ & 5 & 160,17 \\
\hline 5 & $14.310,00$ & 65,05 & 11,5 & 748,02 & 0 & 7 & 243 & 800 & $3.997,05$ & 6 & 95,17 \\
\hline 6 & $14.310,00$ & 65,05 & 5,73 & 372,71 & 0 & 10 & 460 & 400 & $5.372,71$ & 5 & 107,45 \\
\hline 7 & $7.155,00$ & 32,52 & 41,16 & $1.338,64$ & 300 & 22 & 155 & $2.000,00$ & $13.348,64$ & 4 & 151,69 \\
\hline 8 & $7.155,00$ & 32,52 & 37,73 & $1.227,08$ & 350 & 14 & 0 & $2.800,00$ & $8.927,08$ & 4 & 159,41 \\
\hline 9 & 0 & 0 & 12,63 & 0 & 0 & 9 & 60 & 400 & 940 & 3 & 34,81 \\
\hline 10 & $1.431,00$ & 6,5 & 48 & 312,22 & 0 & 2 & 0 & $1.000,00$ & $1.312,22$ & 2 & 328,05 \\
\hline 11 & $1.431,00$ & 6,5 & 11,86 & 77,14 & 0 & 6 & 135 & 200 & $1.087,14$ & 3 & 60,4 \\
\hline 12 & 0 & 0 & 4,2 & 0 & 0 & 7 & 14 & 200 & 298 & 2 & 21,29 \\
\hline 13 & $7.155,00$ & 32,52 & 17,13 & 557,11 & 0 & 6 & 33 & 400 & $1.155,11$ & 3 & 64,17 \\
\hline 14 & $2.385,00$ & 10,84 & 34,06 & 369,24 & 300 & 10 & 460 & $2.400,00$ & $10.369,24$ & 5 & 207,38 \\
\hline 15 & 0 & 0 & 11,16 & 0 & 240 & 4 & 60 & 160 & $1.360,00$ & 2 & 170 \\
\hline 16 & $3.816,00$ & 17,35 & 8 & 138,76 & 450 & 10 & 330 & $4.000,00$ & $11.938,76$ & 4 & 298,47 \\
\hline 17 & $7.155,00$ & 32,52 & 37,73 & $1.227,08$ & 30 & 10 & 0 & 400 & $1.927,08$ & 3 & 64,24 \\
\hline 18 & $3.816,00$ & 17,35 & 40,66 & 705,27 & 300 & 8 & 425 & $1.200,00$ & $7.705,27$ & 4 & 240,79 \\
\hline 19 & 0 & 0 & 11,16 & 0 & 200 & 8 & 145 & 240 & $3.000,00$ & 3 & 125 \\
\hline 20 & $3.816,00$ & 17,35 & 34,8 & 603,62 & 300 & 13 & 150 & $1.200,00$ & $7.653,62$ & 5 & 117,75 \\
\hline 21 & $7.155,00$ & 32,52 & 50 & $1.626,14$ & 450 & 12 & 0 & $1.600,00$ & $8.626,14$ & 5 & 143,77 \\
\hline 22 & $1.431,00$ & 6,5 & 31,43 & 204,44 & 120 & 2 & 80 & 800 & $1.404,44$ & 2 & 351,11 \\
\hline 23 & 0 & 0 & 3,83 & 0 & 220 & 9 & 50 & $4.100,00$ & $6.530,00$ & 2 & 362,78 \\
\hline 24 & $3.816,00$ & 17,35 & 41,16 & 713,94 & 400 & 20 & 40 & $1.280,00$ & $10.793,94$ & 5 & 107,94 \\
\hline 25 & $3.816,00$ & 17,35 & 11,5 & 199,47 & 0 & 3 & 65 & 400 & 794,47 & 2 & 132,41 \\
\hline 26 & $7.155,00$ & 32,52 & 19,63 & 638,42 & 200 & 10 & 100 & 500 & $4.138,42$ & 2 & 206,92 \\
\hline 27 & $1.431,00$ & 6,5 & 34,8 & 226,36 & 250 & 10 & 200 & $1.700,00$ & $6.426,36$ & 4 & 160,66 \\
\hline 28 & 904 & 4,11 & 17,8 & 73,14 & 240 & 1 & 100 & 600 & $1.086,28$ & 6 & 181,05 \\
\hline 29 & $3.816,00$ & 17,35 & 41,16 & 713,94 & 530 & 7 & 300 & $1.200,00$ & $7.723,94$ & 5 & 220,68 \\
\hline 30 & $7.155,00$ & 32,52 & 11,5 & 374,01 & 0 & 12 & 90 & 400 & $1.854,01$ & 5 & 30,9 \\
\hline 31 & $2.385,00$ & 10,84 & 11,56 & 125,32 & 0 & 15 & 100 & 360 & $1.985,32$ & 2 & 66,18 \\
\hline 32 & $7.155,00$ & 32,52 & 11,16 & 362,95 & 450 & 2 & 100 & 240 & $1.702,95$ & 2 & 425,74 \\
\hline 33 & $2.385,00$ & 10,84 & 11,16 & 120,98 & 150 & 2 & 200 & 400 & $1.220,98$ & 4 & 152,62 \\
\hline
\end{tabular}

Total em R\$

$5.355,61$

Legendas: $R m$ : Renda média mensal $(\mathrm{R} \$)$; Re: Renda média por hora $(\mathrm{R} \$) ; D$ : Dias de hospedagem; G: Valor Diário de Hospedagem; Ct: Custo do tempo de viagem; Tt: Tempo médio da viagem; $P$ : Valor diário $\mathrm{c} /$ transporte e alimentação $(\mathrm{R} \$) ; C v$ : Custo do transporte da viagem de ida e volta; $V v$ : Valor do custo total da viagem $(\mathrm{R} \$)$; $T$ : $\mathrm{n}^{\circ}$ total de visitantes; $V m$ : Valor médio diário gasto por visitantes ao PNMLJ. *Obs: Apesar do tempo médio total de viagem $(T t)$ ter sido informado pelos entrevistados, optou-se por utilizar os dados do Google Maps para padronizar os valores.

A soma total do "Valor médio diário gasto por visitantes ao PNMLJ" (R\$ $5.355,61$ ) divididos pelo número total de turistas entrevistados (33) gerou um valor diário de uso do PNMLJ de $\mathrm{R} \$ 162,29$. Esse valor, multiplicado pelo número de 
turistas que frequentaram a área do PNMLJ por ano (159.573 turistas) resultou no valor de uso anual do PNMLJ de $\mathrm{R} \$ 25.897 .102,17$.

Considerando a margem de erro (17\%) e a margem de confiança (95\%) e que $100 \%$ da amostra visitou o PNMLJ, podemos inferir ainda que o valor de uso do PNMLJ anualmente varia entre $R \$ 21.494 .594,80$ e $R \$ 30.299 .609,54$. Esse intervalo de valores faz-se importante, pois ele pode englobar supostamente os turistas que visitam o parque e que não foram contabilizados no universo amostral.

No caso de transferência de estimativas se recomenda utilizar o valor estimado de uso diário do PNMLJ por turista de $R \$ 162,29$. Uma vez que esse valor pode ser multiplicado pelo número de visitantes por ano, estimados para outro lugar (parque, UC, local turístico, etc.), resguardando-se as mesmas características ecossistêmicas do PNMLJ, usado nesse estudo. Entretanto, é importante observar também que esse valor de uso diário por turistas está relacionado a uma região geográfica especifica.

O turismo, importante setor da economia da Zona Costeira, pode migrar de região juntamente com a qualidade dos serviços ofertados a ele, principalmente no que diz respeito aos serviços ecossistêmicos aqui abordados. A pesquisa informou (ver dados completos no Google Drive) que a presença de esgoto (35\%) e de lixo (35\%) são condições negativas para o retorno dos turistas a um local visitado. Os aspectos positivos mais apontados, para o retorno, foram a tranquilidade (21\%), a limpeza (20\%), a balneabilidade (18\%) e a natureza preservada do local (16\%), entre outros. Esse fato chama a atenção para a conservação dos serviços ecossistêmicos da região costeira, principalmente a parcela que tem interesses econômicos. Somado a isso, a regulação do turismo, que apesar de ser sazonal, deve ser instituída para garantir a qualidade e a existência dos benefícios oriundos dos SEs.

\section{Considerações Finais}

A escolha do PNMLJ, como estudo de caso, foi providencial para a elaboração dessa pesquisa, uma vez que ele abrange uma série de serviços ecossistêmicos comuns na Zona Costeira, em específico os relacionados à cultura, lazer e a recreação, desfrutados pelos turistas que frequentam o local.

O estudo propõe, além de estabelecer o valor econômico desses serviços, um referencial para que novas valorações econômicas ecossistêmicas, em ambientes naturais similares, possam ser realizadas. 
O valor econômico anual estimado de $R \$ R \$ 25.897 .102,17$ atribuído ao Uso do PNMLJ, pode não parecer significativo, tratando-se da própria natureza. Contudo, hipoteticamente, em termos econômicos, esse valor se multiplica a cada ano, acrescido ainda, da variação econômica do mercado financeiro.

Mas por que valorar economicamente os SEs, por não se dizer a própria natureza? Esse estudo tem por intuito demonstrar a importância da preservação desses SEs provedores do bem-estar humano para a manutenção da economia do setor turístico entre outros. E dessa forma, propor a taxação do uso dos SEs para a sua preservação e o seu uso sustentável.

Aos tomadores de decisão e gestores de áreas naturais remanescentes na Zona Costeira, cabe utilizar dos conhecimentos aqui expostos (serviços ecossistêmicos e sua estimativa de valor econômico pelo seu uso) para acelerar os processos efetivos de preservação dessas áreas, seja por meio da elaboração e efetivação de planos de manejo; criação de novas UCs; estimativa de valor para compensações ambientais; contribuição financeira pelo uso dos SEs, e aplicação desses na manutenção e conservação dos ecossistemas; fator de mensuração econômica comparativa, no caso da futura perda do SEs pela instalação de um empreendimento; valor de referência para aplicação de multas no caso de danos ambientais em ecossistemas que forneçam SEs similares; entre outros.

Conhecer os SEs da Zona Costeira, seus benefícios ao bem-estar humano e associá-los a um valor econômico pode atribuir um coeficiente a mais na importância para a preservação desses recursos. Tratá-los como um conjunto de valores, representantes do patrimônio natural, demonstra matematicamente, assim como as oscilações do mercado financeiro, que podemos, por meio de manutenção e preservação, agregar valor aos ecossistemas naturais, ou ao contrário, por meio do descaso, do uso inadequado e da falta de gestão apropriada, transformá-los em passivos, colocando em risco, especificamente a qualidade da vida humana que usufrui desses SEs.

\section{REFERÊNCIAS}

ANGELO, Priscila Garcia. Estimativa do valor econômico-ecológico da planície de inundação do Rio Araguaia e influência do público-alvo na valoração ambiental. Dissertação de Mestrado Ecologia e Evolução do Instituto de Ciências Biológicas da Universidade Federal de Goiás. Goiânia, 2010 
BRANT, Francisco Formagini. Valoração Econômica Ambiental como Estratégia de Conservação dos Recursos Hídricos da Bacia Hidrográfica do Rio Macaé - Uma Proposta Metodológica. Dissertação de Mestrado - Instituto Federal de Educação, Ciência e Tecnologia - Fluminense / IFF [Macaé] 2011.

CASTRO, J.W. de A.; Valentini, E.; Rosman, P.C.C. Estudo diagnóstico do comportamento atual da linha de costa entre os rios Pacoti e Tabuba, CE. 37은 Congresso Brasileiro de Geologia. São Paulo, dez. 1992. Boletim de resumos expandidos, v.1. Simpósios, 1992, p. 27

CICES - COMMON INTERNATIONAL CLASSIFICATION OF ECOSYSTEM SERVICES for Integrated Environmental and Economic Accounting. European Environment Agency (EEA). Disponível em: https://cices.eu/resources/. Acesso em 02/07/2018.

CORRÊA, Jacklinne Matta; FERREIRA, Simone Dias. Valorização ambiental: proposição do método de valorização para Estação Ecológica Maracá-Jipióca. Trabalho de Conclusão de Curso (graduação) - Fundação Universidade Federal do Amapá, Coordenação do Curso de Bacharelado em Ciências Ambientais. 58 p. Macapá, 2013.

COSTANZA, Robert; Groot, Rudolf de; Braat, L.; Kubiszewski, Ida; Fioramonti, Lorenzo; Sutton, Paul; Farber, Steve; Grasso, Monica. Twenty years of ecosystem services : How far have we come and how far do we still need to go? In: Ecosystem Services 28 (2017). p. 1-16. Disponível em: http://www.robertcostanza.com/wpcontent/uploads/2017/02/2017_J_Costanza-et-al.-20yrs.-EcoServices.pdf. Acesso em 03/03/2018.

CSF - Conservation Strategy Fund. Valoração dos Serviços Ecossistêmicos: Classe de Valores. Vídeos educativos. Disponível em: https://www.conservation-strategy.org/pt/csfecon-video-lessons/pt. Acesso em: 04/03/2018

FINCO, Marcus Vinícius Alves \& ADBDALLAH, Patrízia Raggi. Valoração Econômica do Meio Ambiente: O Método do Custo de Viagem Aplicado ao Litoral do Rio Grande do Sul. Teoria e Evidência Econômica, vol. 10, no 18, maio, 2002. Disponível em: http://repositorio.furg.br/bitstream/handle/1/906/Valora\%c3\%a7\%c3\%a3o\%20econ\%c3\%b4 mica\%20do\%20meio\%20ambiente.pdf?sequence $=1$.

FONSECA, Reinaldo Aparecida; LIMA, Adriana Barreto; REZENDE, José Luiz Pereira de. Métodos de valoração dos bens e serviços ambientais: uma contribuição para o desenvolvimento regional sustentável. Eixo temático: 3 . Desenvolvimento regional. In: $4^{\circ}$ Congresso Internacional Governo, Gestão e Profissionalização em Âmbito Local Frente aos Grandes Desafios de Nosso Tempo. Belo Horizonte, Brasil, 2013.

GOOGLE MAPS. Aplicativo de pesquisa e visualização de mapas e imagens de satélite. Disponível em https://www.google.com.br/maps. Acesso em 17/03/2019.

GROOT, Rudolf de; WILSON, Matthew; BOUMANS, Roelof. A typology for the classification, description and valuation of ecosystem functions, goods and services. Ecological $\quad 2002 . \quad$ Disponível em: https://www.researchgate.net/publication/297563783_A_Typology_for_the_Classification_De scription_and_Valuation_of_Ecosystem_Functions_Goods_and_Services.

LIMA, A. de S., FIGUEIROA, A. C., GANDRA, T. B. R., PEREZ, B. H. M., SANTOS, B. A. Q., SCHERER, M. E. G. Informação de base ecossistêmica como ferramenta de apoio à gestão costeira integrada da llha de Santa Catarina, Brasil. Desenvolvimento e Meio Ambiente, v. 44, p. 20-35, 2018.

MAYNARD, Simone; James, David; Davidson, Andrew. The Development of an Ecosystem Services Framework for South East Queensland. Environmental management. 2010. 
MEA - MILLENNIUM ECOSYSTEM ASSESSMENT. Ecosystems and Human Well-Being: Synthesis. Washington, Island Press, 2005.137p.

MMA. Ministério do Meio Ambiente. Gerência de Biodiversidade Aquática e Recursos Pesqueiros. Ecossistemas costeiros e marinhos no Brasil. Caracterização da Zona Costeira e Marinha. Panorama da conservação dos ecossistemas costeiros e marinhos no Brasil. Brasília: MMA/SBF/GBA, 2010. 148 p.

OCHOA, Carlos. Marketing and Innovation Manager da Netquest. Specialist in Online Market Research, Online Panels, Technological Product Management, Online Marketing. Disponível em: https://www.netquest.com/blog/br/blog/br/qual-e-o-tamanho-de-amostra-quepreciso . Acesso em 15/11/2018.

PIRES, Juliana. O potencial de florianópolis no desenvolvimento do turismo de negócios e eventos. Monografia apresentada ao Curso de Ciências Econômicas, na Universidade Federal de Santa Catarina UFSC. Florianópolis. 2015.

PMF (2016). Prefeitura Municipal de Florianópolis. Lei no 9948, de 07 de janeiro de 2016. Dispõe sobre a criação da unidade de conservação Parque Natural Municipal Lagoa do Jacaré das Dunas do Santinho. Disponível em: http://leismunicipa.is/fmqup. Acesso em 22/03/2018.

SILVA, Otelino Nunes da. O urbano em um ambiente praial - transformações socioespaciais na localidade do Santinho ocorridas pós década de 70 . Monografia apresentada ao Curso de Geografia da Universidade Federal de Santa Catarina. 2010. $138 p$.

SILVA, Rubicleis G. Valoração do parque ambiental "Chico Mendes", Rio Branco - AC: Uma aplicação probabilística do método Referendum com bidding games. Viçosa: UFV, 2003. 125f. Dissertação (Mestrado em Economia Aplicada) - Universidade Federal de Viçosa, 2003. Disponível em: https://www.locus.ufv.br/handle/123456789/9001

SILVEIRA, Vanessa Cotta. Valoração econômica e percepção ambiental da área de proteção ambiental estadual cachoeira das andorinhas - sub-bacia do Rio das Velhas - MG. Dissertação. Programa de Pós-Graduação em Engenharia Ambiental, Universidade Federal de Ouro Preto (UFOP), Ouro Preto, MG. 2011.

SUGUIO, K. 1992. Dicionário de geologia marinha: com termos correspondentes em inglês, francês e espanhol. São Paulo: T. A. Queiroz, 1992. 171 p.

\section{NOTAS DE AUTOR}

\section{CONTRIBUIÇÃO DE AUTORIA}

Otelino Nunes da Silva- Concepção. Coleta de dados, Análise de dados, Elaboração do manuscrito, revisão e aprovação da versão final do trabalho.

Marinez E. G. Scherer- Concepção. Coleta de dados, Análise de dados, Elaboração do manuscrito, revisão e aprovação da versão final do trabalho.

\section{FINANCIAMENTO}

Não se aplica

CONSENTIMENTO DE USO DE IMAGEM

Não se aplica

APROVAÇÃO DE COMITÊ DE ÉTICA EM PESQUISA

Não se aplica 


\section{LICENÇA DE USO}

Este artigo está licenciado sob a Licença Creative Commons CC-BY. Com essa licença você pode compartilhar, adaptar, criar para qualquer fim, desde que atribua a autoria da obra.

\section{HISTÓRICO}

Recebido em: 24-04-2019

Aprovado em: 30-03-2021 